\section{Was ist „extrem"?}

Zunächst einmal vielen Dank für diesen Artikel. Auch wenn das Thema nur sehr oberflächlich behandelt wurde, konnte man doch einen guten Überblick gewinnen.

Da ich selbst seit über fünf Jahren vegan lebe, habe ich mich schon mehr als einmal gefragt, ob es denn vernünftige Studien zum Thema Mundgesundheit und Veganismus gibt, denn fündig bin ich nicht geworden.

Auch ich ärgere mich des Öfteren darüber, was für Behauptungen in Youtube-Videos und Blogs getätigt werden. Denn obwohl ich eine, um Ihrem Wortlaut zu folgen, „extreme“ Veganerin bin, bin ich auch immer noch eine Zahnärztin, die von der positiven Wirkung von Fluorid überzeugt ist und von der erosiven Wirkung von Fruchtsäuren weiß. Und da haben wir auch das eine Wort, das mir übel aufstößt: „extrem“.

Ich weiß, dass der Artikel nicht die Hintergründe des veganen Lebensstils beschreiben wollte. Sollte er auch nicht. Aber er sollte bitte auch nicht gleich urteilen à la „extrem“. Die mit Abstand meisten Veganer führen diesen Lebensstil aus moralischen Gründen unseren Mitlebewesen gegenüber, so wie ich auch.

Für mich ist es extrem, dafür zu bezahlen, dass ein ausgebeuteter Mensch eine ausgebeutete Tiermutter vergewaltigt, sie damit künstlich befruchtet, laufend zu foltern (denn nein, die mit Abstand meisten Tiere stehen nicht, ihres Lebens froh, auf einer Weide), ihr dann das Neugeborene zu entreißen, dieses zu töten, die Muttermilch des Tierbabys aus den entzündeten Eutern zu entnehmen, gleichzeitig erneut zu befruchten und - sobald das arme Geschöpf nicht mehr die Milchleistung bringt, die die Industrie benötigt - diese Mutter zu massakrieren.

Auch wenn so ziemlich jeder auf Nachfrage sagt, dass er ausschließlich beim Biobauen von nebenan seine Milch und sein Fleisch bezieht, wo die Tiere noch auf der Weide stehen, man das alles sehen kann und dort kein Lebewesen leidet. Man sollte bitte vorsichtig sein mit solchen Wörtern wie „extrem“.

Ansonsten, weiter so!

Magda Doumit, Berlin-Schöneberg

\title{
Normaler Sachverstand durch Emotionen ersetzt
}

Ich danke sehr für den Artikel zum Thema Mundgesundheit und Ernährung. Ich würde mir zum Thema Fluorid - Mythen - Hintergründe noch mehr Informationen wünschen. In Kollegenkreisen und im Freundeskreis wird es sehr emotional diskutiert. Mich interessiert sehr, warum es so ist. Was steckt hinter dem Satz: Karies ist keine Fluorid-Mangelerkrankung. Was ist mit den anderen Wirkstoffen in der Zahnpasta? Warum wird das Fluorid so herausgestellt? Was genau ist Fluorid? Was wird über einen Kamm geschert?
Sorge macht mir, dass der normale Sachverstand (wie bei Ernährungsfragen) durch Emotionen und Ausgrenzung ersetzt wird. Nach dem Motto: Denkst Du (also Du konventioneller Zahnarzt) nicht wie ich, bist Du für mich als Patient nicht tragbar.

Mein Wunsch wäre eine Schwerpunkt-Ausgabe. Nicht nur medizinisch, sondern auch kulturell, politisch und spirituell betrachtet.

Dr. Brigitte Jürgensen, Braunschweig

\section{Studie aus Japan}

\section{Passivrauchen kann Kinderzähne schädigen}

Dass Passivrauchen der Gesundheit von nichtrauchenden Mitmenschen schadet, ist inzwischen zur Binsenweisheit geworden. Die gesundheitlichen Schädigungen sind mannigfaltig und ha-

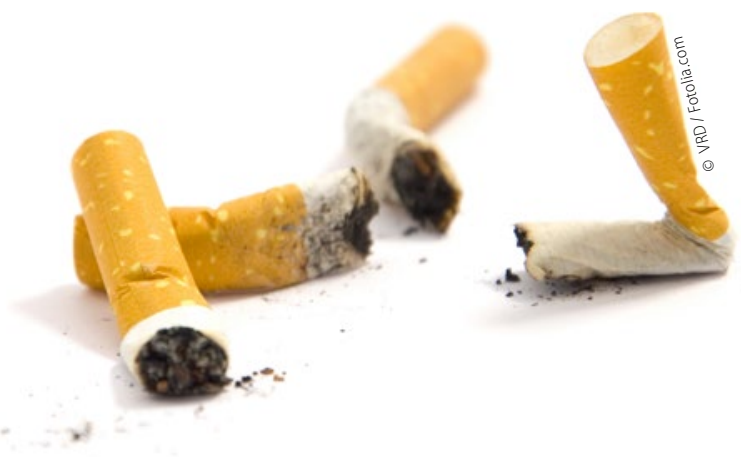

ben sogar Auswirkungen auf die Kariesbildung von Kleinkindern, wie das Fachblatt British Medical Journal berichtet. Demnach hat eine neue bevölkerungsbasierte Studie der Universität Kyoto offengelegt, dass der passive Nikotinkonsum das Risiko von Kindern, an frühkindlicher Karies zu erkranken, verdoppelt. Dafür wurden innerhalb von sechs Jahren die Daten von mehr als 75.000 Kindern ausgewertet. Neben den Ess- und Ernährungsgewohnheiten sowie der Zahnpflege wurde auch der Raucherstatus der Haushalte dokumentiert. Die Forscher berichteten, dass Kinder, die ständig Raucherluft ausgesetzt waren, kariösere Zähne aufgewiesen hätten als Kinder von Nichtrauchern. Das mütterliche Rauchverhalten vor der Geburt habe hingegen keinen Einfluss auf spätere Karies beim Kind gehabt. Bislang sind die Aussagen aus der Beobachtungsstudie noch nicht bewiesen. Um den Einfluss von Zigarettenrauch auf den Zahnstatus endgültig zu klären, sei weitere Forschung nötig, ließen die Autoren der Studie wissen. sas 